NBER WORKING PAPER SERIES

\title{
MERGERS AND THE COMPOSITION \\ OF INTERNATIONAL COMMERCE
}

\author{
Volker Nocke \\ Stephen Yeaple \\ Working Paper 10405 \\ http://www.nber.org/papers/w10405
}

\author{
NATIONAL BUREAU OF ECONOMIC RESEARCH \\ 1050 Massachusetts Avenue \\ Cambridge, MA 02138 \\ March 2004
}

We would like to thank Bruce Blonigen, Bill Ethier, Matt Slaughter, and Scott Taylor for helpful comments. We would also like thank seminar participants at the University of Pennsylvania, Penn State University, Iowa State University, Syracuse University, and the NBER Trade Meetings in Stanford. Finally, both of us gratefully acknowledge financial support through the University of Pennsylvania Research Foundation. The views expressed herein are those of the author(s) and not necessarily those of the National Bureau of Economic Research.

C2004 by Volker Nocke and Stephen Yeaple. All rights reserved. Short sections of text, not to exceed two paragraphs, may be quoted without explicit permission provided that full credit, including (C) notice, is given to the source. 
Mergers and the Composition of International Commerce

Volker Nocke and Stephen Yeaple

NBER Working Paper No. 10405

March 2004

JEL No. F12, F13

\section{ABSTRACT}

In this paper, we develop a novel theory of cross-border mergers and acquisitions. Firms can choose between different modes of foreign market access: exporting, greenfield FDI, and crossborder M\&A. Our theory is based on three key ideas. First, there is heterogeneity in firms' capabilities. Second, these capabilities differ in their degree of international mobility. Third, capabilities are traded in a merger market. We address two questions: (1) what are the characteristics of firms that choose the various modes of foreign market access, and (2) how does the composition of international commerce vary across industries and countries?

We show that the degree to which firms differ in their mobile and non-mobile capabilities plays a crucial role for the composition of international commerce: depending on whether firms differ in their mobile or immobile capabilities, cross-border mergers may involve the most or the least efficient active firms. A similar dichotomy obtains when analyzing the effects of country and industry characteristics on the distribution of firms' efficiencies.

Volker Nocke

University of Pennsylvania

Department of Economics

3718 Locust Walk

Philadelphia, PA 19104

nocke@econ.upenn.edu

Stephen Yeaple

University of Pennsylvania

Department of Economics

3718 Locust Walk

Philadelphia, PA 19104

and NBER

snyeap12@ssc.upenn.edu 


\section{Introduction}

In an increasingly globalized world, the decision of how best to serve foreign markets is becoming one of the key challenges facing firms. A firm that has decided to sell its product abroad has two distinct options of serving foreign markets: exporting or producing locally (foreign direct investment (FDI)). If the firm decides to produce locally, it can choose between building its own establishment (greenfield investment) or to acquire an existing firm (cross-border merger and acquisition (M\&A)). The fundamental difference between cross-border M\&A and greenfield FDI is that cross-border M\&A involves a transaction between a buyer and a seller at an endogenous price, while greenfield FDI is simply an investment decision that does not involve a market transaction and is therefore not directly constrained by market clearing conditions for firm assets.

While the difference between cross-border M\&A and greenfield investment might seem subtle at first glance, there is a belief among the agents who conduct or influence international commerce that these modes are in fact very different. First, a vast business literature suggests that firms view cross-border M\&A and greenfield investment as very different modes of FDI so that the choice between these modes requires careful cost/benefit analysis. Second, as international commerce has increasingly taken the form of foreign direct investment, governments have sought to design policies vis-à-vis foreign firms entering their market. In formulating their approach to the treatment of foreign firms producing in their market, many governments perceive the costs and benefits of the two modes of FDI as very different.

In a number of host countries, concern is expressed in political discussions and the media that FDI entry through the takeover of domestic firms is less beneficial, if not positively harmful, for economic development than entry by setting up new facilities. At the heart of these concerns is that foreign acquisitions do not add to productive capacity but simply transfer ownership and control from domestic to foreign hands. (United Nations Center for Transnational Corporations, 2000, p. xxiii) 


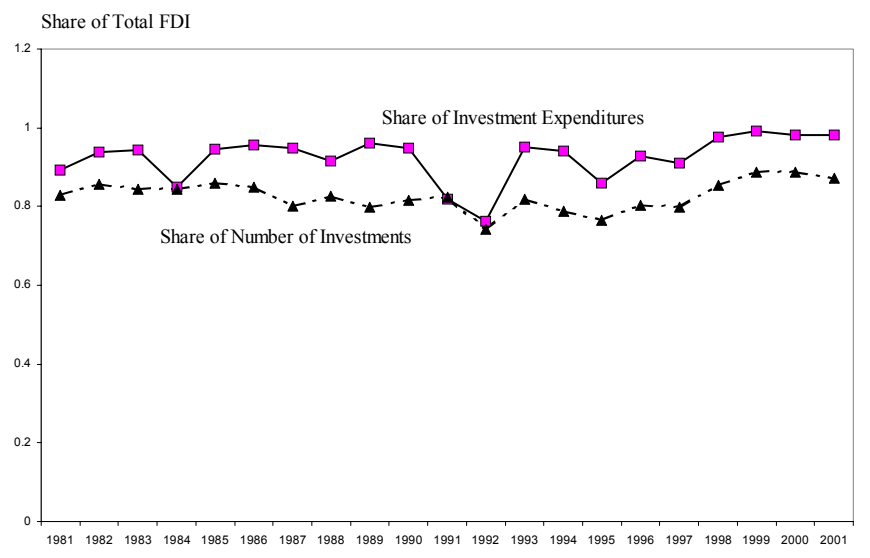

Figure 1: Acquisitions in total manufacturing FDI.

Interestingly, while the CEOs of multinational firms and government policymakers believe that greenfield investment and cross-border M\&A are distinct modes of FDI, the academic literature in International Trade has not distinguished between the two modes. In fact, almost all of the literature has implicitly assumed that FDI takes the form of greenfield. Yet, empirical evidence shows that firms engaging in FDI have entered foreign markets mainly by purchasing existing foreign firms rather than by building new plants. As figure 1 illustrates, in every year from 1981 to 2001, between $75 \%$ and $90 \%$ of all new foreign affiliates in U.S. manufacturing have been acquired by foreign firms (cross-border M\&A), while only 10\% -25\% have been newly established (greenfield investment).

Given the empirical importance of cross-border M\&A, it is worth asking first why mergers occur more generally. According to the business literature, firms differ in their underlying capabilities, and many mergers occur to allow firms to exploit complementarities in these capabilities. In the international context, cross-border mergers often occur because local firms have some capabilities, such as the knowledge of local market conditions that foreign firms lack, while foreign firms bring some other capabilities, such as organizational capital or technology 
to the party. That is, cross-border mergers are frequently motivated by the complementarities between internationally mobile and non-mobile capabilities. Caves (1996, p. 70) summarizes this motive as follows:

The going concern is a working coalition. From the viewpoint of the foreign MNE, it possesses an operating local management familiar with the national market environment. The MNE that buys the local firm also buys access to a stock of valuable information.

A cross-border acquisition thus allows a firm to get costly access to the country-specific capabilities of the acquired firm, and the price of such an acquisition is governed by demand and supply. In contrast, by engaging in greenfield FDI, a firm brings only its own capabilities to work abroad. Different firms will solve this trade-off differently.

One contribution of this paper is to provide a theoretical framework of international commerce in which firms can choose between different modes of foreign market access (exporting vs. greenfield FDI vs. cross-border M\&A). Our framework formalizes the three key ideas developed above. First, there is heterogeneity in firms' capabilities. Second, these capabilities differ in their degree of international mobility. Third, capabilities are traded in a merger market, and so the price of capabilities is determined by (endogenous) supply and demand. We then use this framework to address two questions: (1) what are the characteristics of firms that choose these various modes of foreign market access, and (2) how does the composition of international commerce vary across industries and countries?

The three key ideas on which our framework builds have important consequences for our understanding of international commerce.

First, because we distinguish between mobile and non-mobile capabilities we are able to identify a unique motive for firms to engage in FDI: to obtain non-mobile capabilities in other countries. We find that as capabilities become relatively less mobile internationally that crossborder M\&A becomes the favored mode of entry into foreign markets. Given the relative importance of cross-border M\&A in total FDI, our framework suggests that a key motive for FDI is to obtain non-mobile capabilities. To our knowledge, the empirical Trade literature 


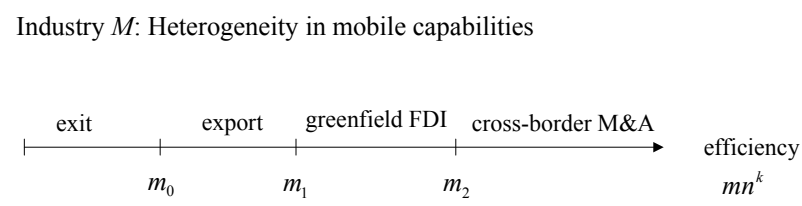

Industry $N$ : Heterogeneity in non-mobile capabilities

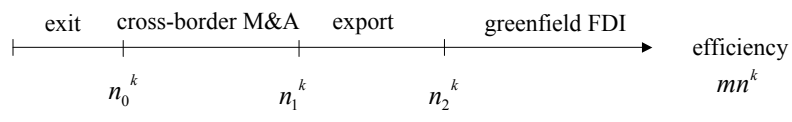

Figure 2: The composition of international commerce by industry type.

ignores the role of non-mobile capabilities in the trade-off between exports and FDI.

Second, we show that the source of firm heterogeneity is a critical determinant of the composition of international commerce. While firms have long been known to differ within industries in terms of their observed efficiency, the underlying source of this heterogeneity is likely to differ across industries. In industries where firms differ mainly in their mobile capabilities, the most efficient firms will engage in cross-border M\&A, while in industries where firms differ mainly in their country-specific non-mobile capabilities, cross-border M\&A will involve the least efficient active firms. The composition of international commerce for the two types of industries is illustrated in figure 2 .

This dichotomy has wide-ranging implications for empirical work. A small but fast growing empirical literature seeks to understand the relationship between a firm's characteristics and its choice of mode of serving foreign markets. By and large, researchers impose a single mapping from firm characteristics to mode choice across industries and obtain mixed results. Our theory suggests the common procedure of pooling industries in regression analyses is inappropriate as the mapping from firm characteristics to mode choices differs qualitatively across industries in 
a systematic fashion.

Third, we show that the presence of a merger market clearing condition for country-specific capabilities has wide ranging implication for the effect of other country and industry characteristics on the distribution of efficiencies within an industry. In our model, foreign firms demand local non-mobile capabilities which are in turn supplied by local firms. Mergers thus have a direct effect on the nature of firms producing in a country and so influence aggregate industry efficiency. To the extent that changes in country and industry characteristics alter the supply and demand for local non-mobile capabilities, the effect of changes in these characteristics is mediated by the merger market. In models without cross-border M\&A, the effect of country and industry variables on aggregate industry efficiency can be dramatically different. Our results are thus of interest to a growing empirical research into the effect of international commerce on aggregate industry efficiency.

Related Literature. Our paper contributes to a growing literature that analyzes the endogenous selection of heterogeneous firms into modes of foreign market entry. ${ }^{1}$ Within this literature, the paper that is closest in spirit to ours is Helpman, Melitz, and Yeaple (2004) who consider only two modes of foreign market entry: exports and greenfield FDI. The key differences between our paper and that of Helpman et al. (HMY) is that (i) we introduce the idea that not all types of capabilities are perfectly mobile internationally, and (ii) in our model, firms can trade capabilities in a merger market. By considering both mobile and non-mobile capabilities, our framework (1) gives rise to cross-border M\&A, and (2) yields different predictions on the composition of international commerce. In HMY, firms that engage in FDI are the most efficient firms within an industry. In contrast, we find that firms conducting FDI via cross-border M\&A are the least efficient active firms when the source of firm heterogeneity is due to non-mobile capabilities. We also find that the merger market clearing condition, not present in HMY, has important implications for the effect of country and industry characteristics on the distribution of firm efficiencies. For example, in HMY, the mapping from a firm's efficiency to its mode of foreign market access is independent of the size of a country, while in

\footnotetext{
${ }^{1}$ A key paper in this literature is Melitz (2003) who analyzes the decision of firms to enter foreign markets by becoming exporters. Other important papers include Bernard et al. (2003) and Antras and Helpman (2003).
} 
our setting, size must matter for the merger market to clear.

Our paper also contributes to the industrial organization literature on endogenous horizontal mergers. In contrast to our paper, this literature has mainly been concerned with market power as the driving force of mergers, and with the limits of monopolization through acquisition (e.g., Kamien and Zang (1990), Nocke (2000)). One notable exception is the paper by Jovanovic and Rousseau (2002), where acquisitions are modeled as the outcome of a stochastic productivity process in which firms receiving bad technology shocks sell their capacity to more efficient firms. The literature on cross-border M\&A is still in its infancy, and authors in this literature have also focused on market power as the motivation for mergers (e.g., Head and Ries (1997), Horn and Persson (2001), Neary (2003)). ${ }^{2}$

Outline. The plan of the paper is as follows. In the next section, we describe in detail our theoretical framework. Then, in section 3, we turn to the equilibrium analysis. We derive the composition of international commerce and show how it depends on the source of firm heterogeneity. In section 4, we investigate the effects of country and industry characteristics on the composition of international commerce and the distribution of firm efficiencies. We conclude in section 5 .

\section{The Model}

We consider a model of international trade with two countries, 1 and 2 , indexed by $k$ (and sometimes $l$ ). The aggregate income level in country $k$ is denoted by $Y^{k}$. We assume that the two countries are of similar size so that $\left|Y^{1}-Y^{2}\right|$ is small. The countries are identical in all other respects. In particular, the price of labor is the same in both countries, and normalized to 1. The assumption of equal wages follows from the existence of an outside good that is produced by both countries and requires only labor.

Preferences. The representative consumer has two-tier preferences: Cobb-Douglas preferences over the homogeneous outside good and two types of differentiated goods, $M$ and $N$,

\footnotetext{
${ }^{2}$ An important early contribution on exogenous cross-border mergers is Markusen (1984). He analyzes the exogenous merger of two competing national firms and the resulting welfare effects.
} 
and CES preferences over varieties of each differentiated good. She spends a fraction $\beta_{i}$ of her income on the differentiated goods industry $i \in\{M, N\}$. Her sub-utility over the varieties of the differentiated good $i \in\{M, N\}$ can be written as

$$
X_{i}^{k}=\left[\int_{\omega \in \Omega_{i}^{k}} q_{i}^{k}(\omega)^{1-\rho_{i}} x^{k}(\omega)^{\rho_{i}} d \omega\right]^{\frac{1}{\rho_{i}}}, \quad \rho_{i}=\frac{\sigma_{i}-1}{\sigma_{i}}, \sigma_{i}>1,
$$

where $x^{k}(\omega)$ and $q^{k}(\omega)$ are the level of consumption and the perceived quality of variety $\omega$, respectively, and $\sigma_{i}$ the elasticity of substitution across varieties.

Firms. Each firm produces one unique variety at constant marginal costs of production. Firms differ in their capabilities. There are two types of capabilities: mobile and non-mobile. The efficiency of a firm's production technology is assumed to be mobile internationally. There is an inverse relationship between a firm's mobile capability $\widetilde{m}_{i}$ and a firm's marginal cost $c\left(\widetilde{m}_{i}\right)$ :

$$
c\left(\widetilde{m}_{i}\right)= \begin{cases}\frac{1}{\widetilde{m}_{i}} & \text { if } \widetilde{m}_{i}>0 \\ \infty & \text { otherwise. }\end{cases}
$$

In contrast to technology, marketing expertise is assumed not to travel well. Firm's differ in the quality of their marketing expertise, and the better the marketing expertise, the higher is the perceived quality of the good. To emphasize the observation that marketing expertise is not perfectly mobile internationally, we refer to a firm's marketing expertise as the firm's non-mobile capability $n_{i}^{k}$. The firm's perceived quality in country $k$ is given by

$$
q^{k}(\omega)=\max \left\{n_{i}^{k}(\omega), \delta_{i} n_{i}^{l}(\omega)\right\} \text { for } l \neq k
$$

where $\delta_{i} \in(0,1)$. The idea here is that $n_{i}^{k}$ is a measure of quality of the firm's marketing team (or distribution network, sales force etc.) in country $k$. Ceteris paribus, a marketing team is better in its home country than abroad: this is captured by the degree of mobility $\delta_{i}$. Indeed, there is recent empirical evidence suggesting that domestic firms have an advantage over foreign firms in marketing activities in their own country; see Maurin, Thesmar, and Thoenig (2002). ${ }^{3}$

\footnotetext{
${ }^{3}$ We have chosen a particular route in modeling non-mobile capabilities. In a previous version of this paper, we took a different route in assuming that there are two stages of production, (i) the production of an intermediate input and (ii) assembly. Only (i) was assumed to require scarce capabilities. In contrast to the current set-up,
} 
Both mobile and non-mobile capabilities are industry-specific and can only be used by one firm at any time. Production and marketing have to be undertaken within the firm. A firm owning a collection of capabilities, can use no more than one capability of each type (non-mobile capability for each country, and mobile capability). Therefore, a firm can be defined by its ownership of its best mobile and non-mobile capabilities, $\left\{n_{i}^{1}, n_{i}^{2}, \widetilde{m}_{i}\right\}$, and by its home country. For convenience, we call a firm's home country the country in which the firm's capability $\widetilde{m}_{i}$ was originally (i.e., upon entry) created.

If firms ship the final output from one country to another, iceberg-type transportation costs have to be incurred: for one unit to arrive in the foreign country, $\tau_{i}>1$ units need to be shipped. The existence of these transportation costs (or tariffs) makes the cost of serving a market sensitive to the location of production. If the good is produced in country $k$ and then shipped to country $l \neq k$, the marginal cost of serving country $l$ is $\tau_{i} c\left(\widetilde{m}_{i}\right)$.

In addition to the variable costs, fixed (corporate management) costs have be incurred by multinational firms. First, there is a fixed coordination cost $F_{c, i}$ that has to be incurred whenever the marketing team and the production of the good are in different locations. This coordination cost need not be incurred if (i) production takes place only in country $k$ and the firm uses a country- $k$ marketing team, and (ii) production takes place in both countries and the firm uses a marketing team in each country. Second, there is a fixed cost $F_{f, i}$ of managing a foreign marketing team.

For notational convenience, we will henceforth work with the following transforms of $\widetilde{m}_{i}$ and $\tau_{i}$ :

$$
m_{i} \equiv \widetilde{m}_{i}^{\sigma_{i}-1} \quad \text { and } T_{i} \equiv \tau_{i}^{-\left(\sigma_{i}-1\right)}
$$

The benefit of these transformations is that a firm's profit is linear in the redefined variables. Note that $T_{i}<1$ is inversely related to $\tau_{i}$, while $m_{i}$ is positively related to $\widetilde{m}_{i}$.

Entry. There is a continuum of (atomless) potential entrants, each of which is endowed with the know how to produce a unique variety. Entrants can only enter the market in their own country. If they decide to do so, they have to pay an (irrecoverable) entry fee $F_{e, i}$. After

however, non-mobile capabilities were completely country-specific. Consequently, greenfield FDI was restricted to assembly abroad. However, almost all of the results of the two set-ups are identical. 
a firm has paid the entry cost, it gets a random draw of its (local) non-mobile (marketing) capability $\left(n_{i}^{k} \geq 0\right.$ for an entrant in country $\left.k\right)$, and of its mobile capability $\left(m_{i} \geq 0\right)$. A new entrant in country $k$ is assumed to have no marketing expertise specific to the other country, i.e., $n_{i}^{l}=0$ for $l \neq k$. This captures in a tractable manner the idea that firms have an advantage in acquiring capabilities specific to their own home country.

We assume that capabilities of an entrant in country $k, n_{i}^{k}$ and $m_{i}$, are independently distributed. Industries are likely to differ in the underlying source of heterogeneity between firms. To isolate the implications of heterogeneity in the different types of capabilities, we assume that in industry $M$ the underlying source of heterogeneity is in firms' mobile capabilities, while in industry $N$ it is in firms' non-mobile capabilities. In both industries, the "good" mobile and non-mobile capabilities are scarce.

Industry $M$ There is heterogeneity in firms' mobile capabilities $\left(m_{M}\right)$, while the distribution of firms' non-mobile capabilities $\left(n_{M}^{k}\right)$ is degenerate. More precisely, for an entrant in country $k$,

$$
\begin{aligned}
& n_{M}^{k}=\left\{\begin{array}{rr}
1 & \text { with probability } \mu, \\
0 & \text { with probability } 1-\mu,
\end{array}\right. \\
& m_{M} \sim H(\cdot) \text { continuous with support }[0, \infty) \text {. }
\end{aligned}
$$

Industry $N$ There is heterogeneity in firms' non-mobile capabilities $\left(n_{N}^{k}\right)$, while the distribution of firms' mobile capabilities $\left(m_{N}\right)$ is degenerate. More precisely, for an entrant in country $k$,

$$
\begin{aligned}
& m_{N}=\left\{\begin{array}{rr}
1 & \text { with probability } \nu, \\
0 & \text { with probability } 1-\nu,
\end{array}\right. \\
& n_{N}^{k} \sim G(\cdot) \text { continuous with support }[0, \infty) .
\end{aligned}
$$

Each firm can produce only one variety due, for instance, to entrepreneurs' limited span of control (Lucas (1978)). Moreover, any capability can productively be used only by a single firm. 
Merger Market. After firms have entered the market, their endowment of capabilities can be traded in a perfectly competitive merger market. The equilibrium value (or profit) of a firm in home market $k$ with capabilities $\left\{n_{i}^{1}, n_{i}^{2}, m_{i}\right\}$ can be decomposed as

$$
\Pi_{i}\left(n_{i}^{1}, n_{i}^{2}, m_{i}, k\right)=V_{i}^{1}\left(n_{i}^{1}\right)+V_{i}^{2}\left(n_{i}^{2}\right)+W_{i}^{k}\left(m_{i}\right)
$$

where $V_{i}^{k}(n)$ is the market price for capability $n_{i}$ in country $k$ and industry $i$, and $W_{i}^{k}\left(m_{i}\right)$ the market price of capability $m_{i}$ in country $k$ and industry $i$. While a firm is identified by the ownership of its capabilities (and its home country), we do not need to identify the "owner" of the firm who is buying or selling capabilities on the merger market. However, it may be convenient for the reader to identify a firm's ownership with its mobile capability $m_{i}$ (and so only the non-mobile capabilities are traded on the merger market, while $W_{i}^{k}\left(m_{i}\right)$ is the shadow value of $\left.m_{i}\right)$.

Firms and the Post-Merger Location of Production. As we will show in the next section, all firms will locate the production in their home country. Firms will therefore serve their home market entirely from local production. If firms only locate production in their home country, they export their good to the foreign market, incurring iceberg-type transport costs. If firms choose to serve the foreign market by locating production abroad (FDI), they may choose between greenfield FDI and cross-border M\&A. The distinction between these two modes of FDI is that a firm engaging in the former does not acquire a non-mobile capability specific to the foreign country.

Product Market Competition. Since there is a continuum of atomless firms (each facing a downward-sloping demand curve), we may think of firms as either setting prices or quantities. We allow firms to discriminate between markets, so that they can set different prices (or quantities) for the two countries.

Timing. The timing of the model may be summarized as follows.

Entry Stage In each country, potential entrants decide whether or not to enter the market.

Merger Stage Firms participate in the merger market (as buyers or sellers), and decide where to locate production (incurring the associated fixed costs). 
Output stage Firms compete in prices (or quantities) and receive profits.

Equilibrium. Formally, the model may be cast as an anonymous game. We seek the subgame perfect equilibrium of this game.

\section{Equilibrium Analysis: The Composition of International Com- merce}

In this section, we turn to the equilibrium analysis of our model and determine the equilibrium pattern of export, greenfield FDI, and international mergers. We derive firms' payoffs as a function of their capabilities and their mode of foreign market access. We then turn to the equilibrium analysis in each of the two industries. First, we will consider industry $M$, where firms differ in their mobile capabilities. Then, we will analyze industry $N$, where firms differ in their non-mobile capabilities.

Solving the representative consumer's utility maximization problem, we obtain the following demand for any variety of good $i$ in country $k$ :

$$
x^{k}(\omega)=\beta_{i} Y^{k}\left(P_{i}^{k}\right)^{\sigma_{i}-1} q^{k}(\omega) p^{k}(\omega)^{-\sigma},
$$

where $p^{k}(\omega)$ is the price of variety $\omega$ in country $k$, and

$$
P_{i}^{k}=\left[\int_{\omega \in \Omega_{i}^{k}} q^{k}(\omega) p^{k}(\omega)^{1-\sigma_{i}} d \omega\right]^{\frac{1}{1-\sigma_{i}}}
$$

the aggregate price index for good $i$ in country $k$.

Let $\widehat{c}_{i}^{k}(\omega)$ denote the marginal cost of selling variety $\omega$ in country $k$, inclusive of the (icebergtype) transportation cost (if any). Recall that firms can price-discriminate between countries. Profit maximization then implies that each firm charges a fixed markup, and so $p^{k}(\omega)=$ $\widehat{c}_{i}^{k}(\omega) / \rho_{i}$. Hence, the gross profit of a firm selling variety $\omega$ in country $k$ is given by

$$
S_{i}^{k} q^{k}(\omega)\left(\widehat{c}_{i}^{k}(\omega)\right)^{1-\sigma_{i}}
$$

where the markup-adjusted residual demand level $S_{i}^{k}$ is given by

$$
S_{i}^{k}=\frac{\beta_{i} Y^{k}}{\sigma_{i}}\left[\int_{\omega \in \Omega_{i}^{k}} q^{k}(\omega) \widehat{c}_{i}^{k}(\omega)^{1-\sigma_{i}} d \omega\right]^{-1} .
$$


It is straightforward to show that the cross-country differences in the market prices of capabilities are arbitrarily small, given that the two countries are of sufficiently similar size. It then follows that a firm will never produce abroad without also producing at home. To see this, note that the firm could just switch production (including the ownership of the non-mobile capabilities) from one country to the other, and increase its profit by saving on the fixed costs $\left(F_{c, i}\right.$ or $\left.F_{f, i}\right)$, whereas all other components of profits will only change by an arbitrarily small amount. A firm will always serve its home market by locating production at home, and so firms will only differ in their way of serving the foreign market. Further, a firm will never have a marketing team abroad without also having one at home: otherwise, it could sell the foreign marketing team, buy a domestic marketing team, and save the coordination cost $F_{c, i}$. Hence, we are left with three modes of foreign market access: (i) production at home, using a home marketing marketing team (export); (ii) production at home and abroad, using a home marketing team (greenfield FDI), and (iii) production at home and abroad, using a marketing team in each country (cross-border merger).

For each of the three modes of foreign market access, the gross profit of a firm with capabilities $\left\{n_{i}^{1}, n_{i}^{2}, m_{i}\right\}$ that is generated in country $k$ is given by

$$
\begin{array}{ll}
S_{i}^{k} T_{i} \delta n_{i}^{l} m_{i} & \text { for export from country } l \neq k \text { to country } k \\
S_{i}^{k} \delta n_{i}^{l} m_{i} & \text { for greenfield FDI from country } l \neq k \\
S_{i}^{k} n_{i}^{k} m_{i} & \text { for local production and local marketing, }
\end{array}
$$

where $T_{i}=\tau_{i}^{1-\sigma_{i}}<1$.

Our assumptions ensure that we can analyze industries $M$ and $N$ separately. For notational convenience, we henceforth drop the industry subscript $i$.

\subsection{Industry $M$ : Heterogeneity in Mobile Capabilities}

We first consider industry $M$, where mobile capability $m$ is heterogeneous across firms and the distribution of firms' non-mobile capabilities $n^{k}$ is degenerate. Specifically, for an entrant in country $k, m$ is drawn from the continuous and strictly increasing distribution function $H(\cdot)$ 
with density $h(\cdot)$ and support $[0, \infty)$, while $n^{k}=1$ with probability $\mu$ (independently of the realization of $m$ ), and $n^{k}=0$ otherwise.

Since the non-mobile capability $n^{k}=0$ cannot be used for generating profits, its market value must be zero, i.e., $V^{k}(0)=0$. In equilibrium, firms with different mobile capabilities $m$ will take different actions in the merger market. Since each active firm needs exactly one mobile capability $m$, it is convenient to consider the optimal decisions of a firm at the merger stage, conditional on owning a particular $m$ in country $k$. Her payoff from exporting is

$$
w_{x}^{k}(m)=\left(S^{k}+S^{l} T \delta\right) m-V^{k}(1), l \neq k,
$$

where $V^{k}(1)$ is the opportunity cost of using (or the actual cost of purchasing) the domestic non-mobile capability $n^{k}=1$. If, instead, she decides to purchase both a domestic $n^{k}=1$ and a foreign $n^{l}=1$ (cross-border M\&A), she obtains a payoff of

$$
w_{m}^{k}(m)=\left(S^{k}+S^{l}\right) m-V^{k}(1)-V^{l}(1)-F_{f}, l \neq k,
$$

where $F_{f}$ is the fixed cost of managing the foreign marketing team in country $l$. Finally, if she decides to engage in greenfield investment abroad, her expected payoff is

$$
w_{g}^{k}(m)=\left(S^{k}+S^{l} \delta\right) m-V^{k}(1)-F_{c}, l \neq k
$$

where $F_{c}$ is the coordination cost associated with production in country $l$, using a marketing team in country $k$. At the beginning of the merger stage, the value of a firm with mobile capability $m$ in country $k$ is thus

$$
W^{k}(m)=\max \left\{0, w_{x}^{k}(m), w_{m}^{k}(m), w_{g}^{k}(m)\right\} .
$$

Since $W^{k}(m)$ is piecewise linear in $m$ with

$$
0<\frac{d w_{x}^{k}(m)}{d m}<\frac{d w_{g}^{k}(m)}{d m}<\frac{d w_{m}^{k}(m)}{d m}
$$

and

$$
w_{m}^{k}(0)<w_{g}^{k}(0)<w_{x}^{k}(0)<0
$$


there exist (unique) thresholds $m_{0}^{k}, m_{1}^{k}$, and $m_{2}^{k}$ such that a firm with capability $m$ in country $k$ will be inactive if $0 \leq m<m_{0}^{k}$, engaged in exporting abroad if $m_{0}^{k} \leq m<m_{1}^{k}$, engaged in greenfield FDI if $m_{1}^{k} \leq m<m_{2}^{k}$, and engaged in cross-border M\&A if $m \geq m_{2}^{k}$. Hence,

$$
W^{k}(m)=\left\{\begin{array}{cc}
0 & \text { if } m \in\left[0, m_{0}^{k}\right], \\
w_{x}^{k}(m) & \text { if } m \in\left[m_{0}^{k}, m_{1}^{k}\right], \\
w_{g}^{k}(m) & \text { if } m \in\left[m_{1}^{k}, m_{2}^{k}\right], \\
w_{m}^{k}(m) & \text { if } m \in\left[m_{2}^{k}, \infty\right) .
\end{array}\right.
$$

We can summarize the equilibrium sorting of firms as follows.

Proposition 1 In equilibrium, there exist unique thresholds $0<m_{0}^{k} \leq m_{1}^{k} \leq m_{2}^{k}$ such that all firms in industry $M$ and country $k$ with mobile capabilities $m \in\left(0, m_{0}^{k}\right)$ exit, all firms with $m \in\left(m_{0}^{k}, m_{1}^{k}\right)$ engage in exporting, all firms with $m \in\left(m_{1}^{k}, m_{2}^{k}\right)$ engage in greenfield FDI, while all remaining firms with $m>m_{2}^{k}$ engage in cross-border MEGA.

It is straightforward to see that some firms (namely those with high $m$ ) will always engage in cross-border mergers. While parameters may be such that no firm engages in greenfield investment or exporting, it is straightforward to find conditions such that, in equilibrium, there is a positive mass of firms engaging in each of the three modes of foreign market access. For instance, if the fixed cost of entry, $F_{e}$, is sufficiently small (or $T$ sufficiently large) and the fixed cost of managing a foreign marketing team, $F_{f}$, sufficiently large, then each mode of foreign market access will be used by some firms.

Henceforth, we restrict attention to the nonempty parameter space where $0<m_{0}^{k}<m_{1}^{k}<$ $m_{2}^{k}$. In this case, the thresholds are given by

$$
\begin{aligned}
m_{0}^{k} & =\frac{V^{k}(1)}{S^{k}+S^{l} T \delta}, \\
m_{1}^{k} & =\frac{F_{c}}{S^{l}(1-T) \delta} \\
m_{2}^{k} & =\frac{V^{l}(1)+F_{f}-F_{c}}{S^{l}(1-\delta)} .
\end{aligned}
$$

Firms that decide to export are thus less efficient than firms that engage in FDI (through either greenfield investment or cross-border mergers). On the one hand, exports require lower fixed 
costs. On the other, transport costs have to be incurred for each unit shipped abroad, and so the marginal increase in payoff from raising mobile capability $m$ is lower than with FDI. Similarly, firms that engage in greenfield investment suffer from the lower perceived quality relative to firms that purchased a local non-mobile capability, but save the market price of such a capability.

Merger Market Equilibrium. We now consider equilibrium in the merger market. Since each entrant is "born" with one mobile capability $m$, and each active firm needs only one $m$, we may restrict attention to the merger market for non-mobile capabilities.

Let $E^{k}$ denote the mass of entrants in country $k$. Since the probability of $n^{k}=1$ for a new entrant is equal to $\mu$, the supply (through entry) of non-mobile capabilities of type $n^{k}=1$ in country $k$ is $\mu E^{k}$. Each active domestic firm needs a non-mobile capability of type $n^{k}=1$, and so the domestic demand is $E^{k}\left[1-H\left(m_{0}^{k}\right)\right]$. Moreover, all foreign entrepreneurs who decide to engage in cross-border M\&A also require a domestic non-mobile capability of type $n^{k}=1$, and so the foreign demand is $E^{l}\left[1-H\left(m_{2}^{l}\right)\right]$. The clearing condition for the merger market in country $k$ is thus given by

$$
E^{k}\left[\mu+H\left(m_{0}^{k}\right)-1\right]=E^{l}\left[1-H\left(m_{2}^{l}\right)\right], l \neq k
$$

Note that foreign buyers of domestic non-mobile capabilities in the merger market tend to be more efficient (in that they have higher $m$ 's) than domestic buyers: foreign buyers are all firms with $m \geq m_{2}^{l}$, while domestic buyers are those domestic firms with $m \geq m_{0}^{k}$ who received a $n^{k}=0$ upon entry. We now claim that for the merger market to clear the market price of a viable non-mobile capability must be positive: $V^{k}(1)>0$. To see this, note that the right-hand side of the merger market clearing condition, (7), is positive. Since $\mu<1$, for the left-hand side to be positive as well, we must have $m_{0}^{k}>0$, and so, from $(4), V^{k}(1)>0$.

Free Entry. We now turn to firm behavior at the entry stage. Since each potential entrant in country $k$ has the option of not entering and earning zero profits, in equilibrium, potential entrants must be indifferent between entering and not entering. We thus have

$$
\mu V^{k}(1)+\int_{0}^{\infty} W^{k}(m) d H(m)-F_{e}=0
$$


Using (3), the expected value of the mobile capability $m$ is given by

$$
\begin{aligned}
\int_{0}^{\infty} W^{k}(m) d H(m)= & \int_{m_{0}^{k}}^{m_{1}^{k}} w_{x}^{k}(m) d H(m)+\int_{m_{1}^{k}}^{m_{2}^{k}} w_{g}^{k}(m) d H(m)+\int_{m_{2}^{k}}^{\infty} w_{m}^{k}(m) d H(m) \\
= & S^{k} \Psi\left(m_{0}^{k}\right)+S^{l}\left\{T \delta \Psi\left(m_{0}^{k}\right)+(1-T) \delta \Psi\left(m_{1}^{k}\right)+(1-\delta) \Psi\left(m_{2}^{k}\right)\right\} \\
& -V^{k}(1)\left[1-H\left(m_{0}^{k}\right)\right]-F_{c}\left[H\left(m_{2}^{k}\right)-H\left(m_{1}^{k}\right)\right] \\
& -\left(V^{l}(1)+F_{f}\right)\left[1-H\left(m_{2}^{k}\right)\right],
\end{aligned}
$$

where

$$
\Psi\left(m_{i}\right) \equiv \int_{m_{i}}^{\infty} m d H(m)
$$

It will prove useful to rewrite the demand level $S^{k}$, defined by (2), as

$$
S^{k}=\frac{\beta Y^{k}}{\sigma}\left[E^{k} \Psi\left(m_{0}^{k}\right)+E^{l}\left\{T \delta \Psi\left(m_{0}^{l}\right)+(1-T) \delta \Psi\left(m_{1}^{l}\right)+(1-\delta) \Psi\left(m_{2}^{l}\right)\right\}\right]^{-1} .
$$

Equilibrium. Equilibrium in industry $M$ with $0<m_{0}^{k}<m_{1}^{k}<m_{2}^{k}$ can formally be defined as the collection of endogenous variables for each country $k,\left\{V^{k}(\cdot), W^{k}(\cdot), E^{k}, S^{k}, m_{0}^{k}, m_{1}^{k}, m_{2}^{k}\right\}_{k \in\{1,2\}}$, satisfying equations (4) to (10).

\subsection{Industry $N$ : Heterogeneity in Immobile Capabilities}

We now turn to industry $N$, where non-mobile capabilities $\left(n^{k}\right)$ are heterogeneous across firms and the distribution of firms' mobile capabilities $(m)$ is degenerate. Specifically, for an entrant in country $k, n^{k}$ is drawn from the continuous distribution function $G(\cdot)$ with density $g(\cdot)$ and support $[0, \infty)$, while $m=1$ with probability $\nu$ (independently of the realization of $n^{k}$ ), and $m=0$ otherwise.

Since a mobile capability with $m=0$ cannot be used for production, its market value must be zero, i.e., $W^{k}(0)=0$. Consider now a firm which already owns a mobile capability of type $m=1$ in country $k$. The firm may decide to export, the maximum payoff of which is

$$
w_{x}^{k}=\max _{n}\left\{\left[S^{k}+S^{l} T \delta\right] n-V^{k}(n)\right\} .
$$

Let $\Delta_{x}^{k}$ denote the set of non-mobile capabilities that will be used, in equilibrium, for exports. The firm must be indifferent between each of these non-mobile capabilities, and so

$$
\frac{d V^{k}(n)}{d n}=S^{k}+S^{l} T \delta \quad \text { for all } n \in \Delta_{x}^{k} .
$$


Alternatively, the firm may decide to engage in greenfield investment abroad. The maximum payoff of this mode of foreign market access is

$$
w_{g}^{k}=\max _{n}\left\{\left[S^{k}+S^{l} \delta\right] n-V^{k}(n)\right\}-F_{c} .
$$

Denoting by $\Delta_{g}^{k}$ the set of non-mobile capabilities that will be used for greenfield investment, we must have

$$
\frac{d V^{k}(n)}{d n}=S^{k}+S^{l} \delta \quad \text { for all } n \in \Delta_{g}^{k}
$$

to ensure that the firm is indifferent between all the non-mobile capabilities in $\Delta_{g}^{k}$. Finally, the firm may decide to engage in cross-border M\&A, the maximum payoff of which is given by

$$
w_{m}^{k}=\max _{n}\left\{S^{k} n-V^{k}(n)\right\}+\max _{n}\left\{S^{l} n-V^{l}(n)\right\}-F_{f} .
$$

Note that this payoff is independent of the firm's home country, i.e., $w_{m}^{k}=w_{m}^{l}$. Denoting by $\Delta_{m}^{k}$ the set of non-mobile capabilities that will be used for cross-border mergers, we must have

$$
\frac{d V^{k}(n)}{d n}=S^{k} \quad \text { for all } n \in \Delta_{m}^{k}
$$

Next, note that

$$
0<\left.\frac{d V^{k}(n)}{d n}\right|_{n \in \Delta_{m}^{k}}<\left.\frac{d V^{k}(n)}{d n}\right|_{n \in \Delta_{x}^{k}}<\left.\frac{d V^{k}(n)}{d n}\right|_{n \in \Delta_{g}^{k}}
$$

Assuming $W^{k}(1)>0$ (which holds in equilibrium), we must have $V^{k}(n)=0$ for $n$ sufficiently small. That is, the least efficient non-mobile capabilities will not be used in equilibrium. Combining these observations, it follows that there are thresholds $n_{0}^{k}, n_{1}^{k}$, and $n_{2}^{k}$, such that all non-mobile capabilities $n^{k} \in\left[0, n_{0}^{k}\right)$ are not used in equilibrium, all $n^{k} \in\left[n_{0}^{k}, n_{1}^{k}\right)=\Delta_{m}^{k}$ are used for cross-border mergers, all $n^{k} \in\left[n_{1}^{k}, n_{2}^{k}\right)=\Delta_{x}^{k}$ are employed for exports to country $l \neq k$, while all $n^{k} \in\left[n_{2}^{k}, \infty\right)=\Delta_{g}^{k}$ are used for greenfield investment. Hence, in contrast to industry $M$, the firms engaging in cross-border mergers are the least efficient active firms. If one capability is of varying quality, then firms would optimally like to spread the best capabilities over as many units as possible. Cross-border mergers allow mobile capabilities to be used in both countries, whereas country-specific non-mobile capabilities will only be employed in one country. Hence, if there is heterogeneity in the non-mobile capabilities (and homogeneity in 
the mobile capabilities), then cross-border mergers will involve worse capabilities than exports and greenfield investment. In industry $M$, the reverse is true. What remains true is that firms engaging in greenfield investment are more efficient than those who decide to export. The equilibrium sorting of firms can be summarized as follows.

Proposition 2 In equilibrium, there exist unique thresholds $0<n_{0}^{k} \leq n_{1}^{k} \leq n_{2}^{k}$ such that in industry $N$ and country $k$, all non-mobile capabilities $n^{k} \in\left(0, n_{0}^{k}\right)$ exit, all non-mobile capabilities $n^{k} \in\left(n_{0}^{k}, n_{1}^{k}\right)$ are used for cross-border MESA, all non-mobile capabilities $n^{k} \in$ $\left(n_{1}^{k}, n_{2}^{k}\right)$ are used for exports, while all remaining non-mobile capabilities $n^{k}>n_{2}^{k}$ are used for greenfield FDI.

It is straightforward to find conditions such that, in equilibrium, each mode of foreign market access is used by some firms. This holds, for instance, if the coordination cost $F_{c}$ is sufficiently large (or transport costs are sufficiently small so that $T$ is sufficiently close to 1 ) and the fixed cost of managing a foreign marketing team, $F_{f}$, sufficiently small.

Henceforth, we restrict attention to the nonempty subset of the parameter space where $\Delta_{m}^{k}$, $\Delta_{x}^{k}$, and $\Delta_{g}^{k}$ are non-empty, and so

$$
0<n_{0}^{k}<n_{1}^{k}<n_{2}^{k}
$$

Since non-mobile capabilities can be traded, conditional on owning a mobile capability of type $m=1$, each firm is indifferent between exporting, greenfield investment, and cross-border M\&A. This implies

$$
W^{k}(1)=w_{x}^{k}=w_{g}^{k}=w_{m}^{k}
$$

Moreover, since the payoff from cross-border mergers is independent of the firm's home country, $w_{m}^{k}=w_{m}^{l}$, the value of the mobile capability must be the same in both countries:

$$
W^{k}(1)=W^{l}(1) \equiv W(1)
$$

Note that viable mobile capabilities $(m=1)$ are scarce since with positive probability a new entrant obtains a non-viable mobile capability $(m=0)$, whereas all non-mobile capabilities are viable $\left(n^{k}>0\right)$. Hence, $W(1)>0$. 
The market price for non-mobile capabilities, $V^{k}(n)$, can then be written as follows:

$$
V^{k}(n)=\left\{\begin{array}{cc}
0 & \text { if } n \leq n_{0}^{k}, \\
S^{k}\left(n-n_{0}^{k}\right) & \text { if } n \in\left[n_{0}^{k}, n_{1}^{k}\right)=\Delta_{m}^{k}, \\
S^{k}\left(n-n_{0}^{k}\right)+S^{l} T \delta\left(n-n_{1}^{k}\right) & \text { if } n^{k} \in\left[n_{1}^{k}, n_{2}^{k}\right)=\Delta_{x}^{k}, \\
S^{k}\left(n-n_{0}^{k}\right)+S^{l} T \delta\left(n-n_{1}^{k}\right) & \text { if } n^{k} \in\left[n_{2}^{k}, \infty\right)=\Delta_{g}^{k} . \\
+S^{l}(1-T) \delta\left(n-n_{2}^{k}\right) &
\end{array}\right.
$$

The thresholds $n_{i}^{k}$ are thus given by

$$
\begin{aligned}
n_{0}^{k} & =\frac{W(1)+F_{f}-S^{l} n_{0}^{l}}{S^{k}}, \\
n_{1}^{k} & =\frac{S^{l} n_{0}^{l}-F_{f}}{S^{l} T \delta}, \\
n_{2}^{k} & =\frac{F_{c}}{S^{l}(1-T) \delta} .
\end{aligned}
$$

Merger Market Equilibrium. We are now in the position to consider equilibrium in the merger market. Any cross-border merger involves exactly one non-mobile capability from each country. In country $k$, the mass of non-mobile assets used for cross-border mergers is $E^{k}\left[G\left(n_{1}^{k}\right)-G\left(n_{0}^{k}\right)\right]$. Hence, for market clearing, we must have

$$
E^{k}\left[G\left(n_{1}^{k}\right)-G\left(n_{0}^{k}\right)\right]=E^{l}\left[G\left(n_{1}^{l}\right)-G\left(n_{0}^{l}\right)\right]
$$

Moreover, the market for mobile capabilities must clear as well. The world supply of mobile capabilities of type $m=1$ is $\nu\left(E^{k}+E^{l}\right)$. On the demand side, the number of firms in country $k$ engaging in exporting or greenfield investment is $E^{k}\left[1-G\left(n_{1}^{k}\right)\right]$. In addition, in the two countries together, there is a mass $E^{k}\left[G\left(n_{1}^{k}\right)-G\left(n_{0}^{k}\right)\right]=E^{l}\left[G\left(n_{1}^{l}\right)-G\left(n_{0}^{l}\right)\right]$ of firms involved in cross-border mergers. Hence, in equilibrium, ${ }^{4}$

$$
E^{k}\left[1-\nu-G\left(n_{0}^{k}\right)\right]=-E^{l}\left[1-\nu-G\left(n_{1}^{l}\right)\right], l \neq k .
$$

When the two countries are identical, foreign buyers purchase less efficient domestic non-mobile capabilities in the merger market than domestic buyers: foreign buyers purchase $n^{k} \in\left[n_{0}^{k}, n_{1}^{k}\right)$,

\footnotetext{
${ }^{4}$ For each country, there is the additional restriction that $\nu E^{k} \geq E^{k}\left[1-G\left(y_{1}^{k}\right)\right]$. However, since the two countries are assumed to be of sufficiently similar size, this condition is satisfied if (16) holds.
} 
while domestic buyers (who are those firms who received a $n^{k}<n_{0}^{k}$ upon entry) purchase $n^{k} \in\left[n_{0}^{k}, \infty\right)$.

Free Entry. In equilibrium, the value of a new entrant must be equal to zero. This free entry condition can be written as

$$
\nu W(1)+\int_{0}^{\infty} V^{k}(n) d G(n)-F_{e}=0
$$

where

$$
\begin{gathered}
W(1)=S^{k} n_{0}^{k}+S^{l} n_{0}^{l}-F_{f}, \\
\int_{0}^{\infty} V^{k}(n) d G(n)=S^{k} \Phi\left(n_{0}^{k}\right)+S^{l} T \delta \Phi\left(n_{1}^{k}\right)+S^{l}(1-T) \delta \Phi\left(n_{2}^{k}\right),
\end{gathered}
$$

and

$$
\Phi\left(n_{i}\right) \equiv \int_{n_{i}}^{\infty}\left(n-n_{i}\right) d G(n) .
$$

It will prove useful to rewrite the markup-adjusted (residual) demand level $S^{k}$, defined by $(2)$, as

$$
S^{k}=\frac{\beta Y^{k}}{\sigma}\left[E^{k} \Theta\left(n_{0}^{k}\right)+E^{l}\left\{T \delta \Theta\left(n_{1}^{l}\right)+(1-T) \delta \Theta\left(n_{2}^{l}\right)\right\}\right]^{-1}
$$

where

$$
\Theta\left(n_{i}\right) \equiv \int_{n_{i}}^{\infty} n d G(n)=\Phi\left(n_{i}\right)+n_{i}\left[1-G\left(n_{i}\right)\right]
$$

Equilibrium. Equilibrium in industry $N$ with $0<n_{0}^{k}<n_{1}^{k}<n_{2}^{k}$ can formally be defined as the collection of endogenous variables for each country $k,\left\{V^{k}(\cdot), W(\cdot), E^{k}, S^{k}, n_{0}^{k}, n_{1}^{k}, n_{2}^{k}\right\}_{k \in\{1,2\}}$, satisfying equations (11) to (20).

\subsection{Discussion}

In both industries $M$ and $N$, different firms will choose a different mode of foreign market access. However, the theory's predictions on the relationship between a firm's efficiency (as measured by the ratio between perceived quality and marginal cost) and its equilibrium mode of foreign market access are very different for the two industries. In industry $M$, the most efficient firms engage in cross-border M\&A, less efficient firms engage in greenfield FDI, while the least efficient active firms export to the foreign country. In contrast, in industry $N$, it is 
the least efficient active firms that engage in cross-border M\&A, more efficient firms engage in exporting, and the most efficient firms in greenfield FDI. Below, we discuss the economics of the assignment of capabilities, and provide an intuition for the differences in the predictions for the two industries.

To understand the role of mergers in our model, consider a social planner whose objective it is to assemble firms from the existing (post-entry) supplies of mobile and non-mobile capabilities in each country so as to maximize aggregate industry profits (taking as given firms' pricing decisions). Indeed, given our assumption of a perfectly competitive merger market, the equilibrium assignment of capabilities is equivalent to the solution to the planner's problem.

In assigning non-mobile to mobile capabilities, the resource constraint facing the social planner in the two industries is similar in two important respects. First, the social planner can assemble two kinds of firms: (i) firms that use one viable mobile and non-mobile capability (exporters or greenfield FDI), and (ii) firms that use one viable mobile capability in conjunction with one viable non-mobile capability from each country (cross-border M\&A). By doing the latter, the planner allows the firm to avoid transport costs and to use non-mobile capabilities that are specialized for each country. Second, in both industries, there is homogeneity in one type of capability and heterogeneity in the other.

Given the nature of random draws of capabilities at the entry stage, the homogeneous capability is scarce in the sense that the mass of viable homogeneous capabilities is less than the mass of viable heterogeneous capabilities. Hence, the optimal assignment of capabilities in each industry is such that all heterogeneous capabilities below a certain threshold value remain inactive. This threshold capability is directly affected by the mass of capabilities used for crossborder mergers. Cross-border M\&A has thus an important impact on the distribution of firm efficiencies within an industry, which we explore in more detail in the section on comparative statics.

While the mass of viable heterogeneous capabilities exceeds the mass of viable homogeneous capabilities, "low quality" heterogeneous capabilities are imperfect substitutes for "high quality" heterogeneous capabilities. In that sense, the best heterogeneous capabilities are scarce and should thus be used in the most effective manner. The existence of trade frictions in our 
model - transport costs and imperfect mobility of marketing - reduces the effective size of markets. This gives rise to a "superstar phenomenon" (Rosen, 1981): the best heterogeneous capabilities should be assigned to serve the largest markets.

The planner faces a different problem in the two industries as the source of firm heterogeneity is very different. Consider first industry $M$, where the mobile capability $m$ is heterogeneous, and in each country the supply of these capabilities exceeds the supply of the viable homogeneous capability $n^{k}=1$. The existence of trade frictions implies that mobile capabilities used for cross-border mergers serve a larger effective market than those used for either exports or greenfield FDI. Since the best mobile capabilities are the "superstars" in this industry, the social planner optimally assigns the best mobile capabilities to cross-border mergers. Arranging cross-border mergers comes at a cost, however: since each mobile capability is assigned to two scarce non-mobile capabilities (one from each country), it is necessary to increase $m_{0}$, the threshold value of $m$ below which all mobile capabilities are inactive. That is, increasing the number of cross-border mergers comes at the expense of the number of varieties offered.

The trade-offs facing the social planner are very different in industry $N$, where it is the non-mobile capability $n^{k}$ that is heterogeneous, and in each country the supply of all $n^{k}>0$ is greater than the supply of the viable mobile capability $m=1$. Non-mobile capabilities used for cross-border mergers serve a smaller effective market (one country rather than two) than those used for either exports or greenfield FDI. Since the best non-mobile capabilities are the "superstars" in this industry, the social planner optimally assigns the worst active non-mobile capabilities to cross-border mergers. As before, the benefit of a cross-border merger is to avoid trade frictions. Since each cross-border involves two non-mobile capabilities (one from each country) sharing a single mobile capability, an increase in the number of cross-border mergers leads to a lower threshold value $n_{0}^{k}$, below which non-mobile capabilities are inactive.

A key difference between the two industries is therefore that an increase in the volume of cross-border mergers has the opposite effect on the efficiency of the marginal active firm: in industry $M$, it leads to an increase in the quality of the marginal capability used, while in industry $N$, it leads to a decrease. As we will show later, this will play out in very different predictions on the effects of country and industry characteristics on the distribution of firm 
efficiencies. The source of firm heterogeneity matters. ${ }^{5}$

If cross-border mergers were not feasible, the source of firm heterogeneity would not matter: the composition of international commerce would qualitatively be the same in the two industries. Both exporting and greenfield FDI involve mobile and non-mobile capabilities in only one location, but the latter involves no transport costs and hence a larger effective market size. Consequently, in both industries, the more efficient firms should engage in greenfield FDI rather than in exporting.

\section{Comparative Statics}

In this section, we analyze the effects of country and industry characteristics on the composition of international commerce, and on the distribution of firm efficiencies. We show that the source of firm heterogeneity has wide-ranging implications for the effects of country and industry characteristics on the efficiency of the marginal firm.

\subsection{Country Size}

What is the effect of country size on the equilibrium pattern of exports, greenfield FDI, and cross-border M\&A? We address this question by first assuming that countries are initially identical, i.e., $Y^{1}=Y^{2}$, and then considering a small change in country sizes that maintains global income so that $d Y^{k}=-d Y^{l}>0$. The following lemma simplifies our discussion. (All proofs are relegated to the appendix.)

\footnotetext{
${ }^{5}$ By restricting attention to one-sided heterogeneity in each industry, we are able to identify the source of firm heterogeneity as an important industry characteristic for both the composition of international commerce as well as the distribution of firm efficiencies. If we were to assume two-sided heterogeneity in both the mobile and non-mobile capabilities, a complex interaction between countervailing effects would arise. From our discussion of the superstar phenomenon, cross-border mergers should involve the best mobile capabilities and the worst non-mobile capabilities. However, complementarities between mobile and non-mobile capabilities (as assumed in our model) should imply positive assortative matching, i.e., the best non-mobile capabilities should be employed with the best mobile capabilities. But if the best mobile and non-mobile capabilities were involved in crossborder M\&A, the best non-mobile capabilities would wastefully serve only one market. General analytical results for the case of two-sided heterogeneity are unavailable.
} 
Lemma 1 Suppose the two countries are initially of the same size, i.e., $Y^{1}=Y^{2}$, and consider a small change in country sizes such that $d Y^{k}=-d Y^{l}$. Then, the change in any endogenous variable $u$ has the same absolute value in the two countries, but is of opposite sign: $d u^{k}=-d u^{l}$.

We first turn to the effects of changes in country size in industry $M$.

Proposition 3 Consider industry $M$. Suppose the two countries are initially of the same size, i.e., $Y^{1}=Y^{2}$, and consider a small increase in the size of country $k$ (and a small decrease in the size of country $l \neq k$ ) such that $d Y^{k}=-d Y^{l}>0$. Then,

$$
d S^{k}=-d S^{l}>0, \quad d E^{k}=-d E^{l}>0, \quad d V^{k}(1)=-d V^{l}(1)<0,
$$

and

$$
d W^{k}(m)=-d W^{l}(m)\left\{\begin{array}{cc}
>0 & \text { if } m \in\left(m_{0}^{k}, m_{2}^{k}\right), \\
=0 & \text { otherwise, }
\end{array}\right.
$$

where $m_{0}^{k}$ and $m_{2}^{k}$ are the (new) thresholds in the larger market. Furthermore,

$$
d m_{0}^{k}=-d m_{0}^{l}<0, \quad d m_{1}^{k}=-d m_{1}^{l}>0, \quad d m_{2}^{k}=-d m_{2}^{l}>0
$$

We now want to discuss the intuition for these results. Appealing to lemma 1, we focus on the larger country $k$. The direct effect of a redistribution of global income is to raise the markup-adjusted residual demand curve in country $k$. This raises the number of entrants, $E^{k}$. Consider now the merger market clearing condition for country $k$, as given by equation (7),

$$
E^{k}\left[\mu+H\left(m_{0}^{k}\right)-1\right]=E^{l}\left[1-H\left(m_{2}^{l}\right)\right] .
$$

On the l.h.s. is the "net supply" (after domestic mergers) of the viable non-mobile capability $n^{k}=1$, while on the r.h.s. is the foreign demand for this capability. At the initial thresholds, there is now an excess supply of $n^{k}=1$. This causes the market value of this capability to drop, $d V^{k}(1)<0$. Thus it is now more attractive for mobile capabilities to be used in the larger market: demand is higher, $d S^{k}>0$, and non-mobile capabilities are cheaper, $d V^{k}(1)<0$. Firms in the smaller country $l$ will therefore integrate to a larger extent into country $k$, and so $d m_{1}^{l}<0$ and $d m_{2}^{l}<0$. For the same reason, the value of those mobile capabilities in country 
$k$ that are used for exporting or greenfield FDI is now larger, $d W^{k}(m)>0$ for $m \in\left(m_{0}^{k}, m_{2}^{k}\right)$. Consequently, less efficient mobile capabilities will still be used in equilibrium, $d m_{0}^{k}<0$. Since global market size remains unchanged, the value of those mobile capabilities that continue to be used for cross-border M\&A does not change.

We now turn to the effects of changes in country size in industry $N$.

Proposition 4 Consider industry N. Suppose the two countries are initially of the same size, i.e., $Y^{1}=Y^{2}$, and consider a small increase in the size of country $k$ (and a small decrease in the size of country $l \neq k$ ) such that $d Y^{k}=-d Y^{l}>0$. Then,

$$
d S^{k}=-d S^{l}>0, \quad d E^{k}=-d E^{l}>0, \quad d W(1)=0,
$$

and there exists a unique cutoff $\widehat{n} \in\left(n_{0}^{k}, n_{1}^{k}\right]$ such that

$$
d V^{k}(n)=-d V^{l}(n)\left\{\begin{array}{cc}
>0 & \text { if } n>\widehat{n} \\
<0 & \text { if } n \in\left(n_{0}^{l}, \widehat{n}\right)
\end{array},\right.
$$

where $n_{i}^{k}\left(n_{i}^{l}\right)$ refers to a new threshold in market $k(l)$. Furthermore,

$$
d n_{0}^{k}=-d n_{0}^{l}>0, \quad d n_{1}^{k}=-d n_{1}^{l}<0, \quad d n_{2}^{k}=-d n_{2}^{l}>0 .
$$

The direct effect of the redistribution of global income from country $l$ to country $k$ is to raise the markup-adjusted residual demand level $S^{k}$ in country $k$, and to reduce it in country $l$. This direct effect has several immediate implications. First, it follows from equation (14) that $d n_{2}^{k}>0$ : in country $k$, firms switch from greenfield FDI to exporting since the incentive to avoid transport cost is weaker in a smaller market. Second, the value of non-mobile capabilities in each country is altered: as can be seen from equation (11), the increase in $S^{k}$ directly raises the value of all non-mobile capabilities $V^{k}(n)$ in country $k$. In contrast, the shadow value of viable mobile capabilities is unaffected by the redistribution of global income since the value of these capabilities must be the same in both countries. The increase in the value of nonmobile capabilities in country $k$ induces a larger number of entrants, $E^{k}$. The greater supply of non-mobile capabilities depresses their value, and reduces each firm's residual demand. Does the increased number of entrants reduce the markup-adjusted demand level $S^{k}$ and the price 
schedule $V^{k}(n)$ to its initial values? The answer is no. If they were to return to their initial levels, the thresholds $n_{i}^{k}$ would be the same as before, but the number of firms in each country would be different. However, in this case, the merger market would not clear:

$$
E^{k}\left[G\left(n_{1}^{k}\right)-G\left(n_{0}^{k}\right)\right]>E^{l}\left[G\left(n_{1}^{l}\right)-G\left(n_{0}^{l}\right)\right]
$$

as $E^{k}>E^{l}$ and $n_{i}^{k}=n_{i}^{l}$. Intuitively, there is an excess supply of small $n^{k}$ 's, and so their market price must fall. Hence, $d n_{0}^{k}>0$. However, in expectation, the value of an entrant's draw of $n^{k}$ must remain unchanged, as can be seen from the free entry condition. It follows that the market value of large $n^{k}$ s must rise. Despite the larger number of entrants, the residual demand level $S^{k}$ must be larger, and so the incremental value of a slightly better $n^{k}$ increases: the price schedule $V^{k}(n)$ becomes steeper.

General Discussion of Country Effects. There are two important lessons that come out of the above analysis. First, in both industries $M$ and $N$, market size "matters": changes in country size affect the composition of international commerce and the efficiency of the marginal active firm. This is due to the existence of the merger market. In the absence of the merger market, free entry would imply - as in Helpman, Melitz, and Yeaple (2004) - that the markupadjusted residual demand level were the same in both countries, $S^{k}=S^{l}$. Independently of any size difference, the thresholds would be the same as well. As explained above, in our model, the markup-adjusted demand levels cannot be the same in countries of different size since otherwise the cross-border merger market would not clear: there would be an excess supply (demand) of (for) non-mobile capabilities in the larger (smaller) country. ${ }^{6}$

Second, the effect of market size on the distribution of firm efficiencies is very different for different industries as it depends critically on the source of firm heterogeneity. In industry $M$, weaker firms are able to survive in the larger market, while the opposite is true for industry

\footnotetext{
${ }^{6}$ While the merger market is necessary for market size to matter, there is a subtle difference between industries $M$ and $N$. For market size to matter in industry $M$ requires an additional ingredient: the fixed cost $F_{f}$ of managing a foreign marketing team (or some other small friction for cross-border mergers). In contrast, market size would matter for industry $N$ even in the absence of such a fixed cost.
} 
$N .^{7}$

While there is dichotomy between industries $M$ and $N$ regarding the effect of market size on the distribution of firm efficiencies, a common prediction for both industries is that the fraction of entrants who engage in FDI (through either greenfield or cross-border mergers) is smaller in the larger country. This is consistent with the empirical evidence. ${ }^{8}$

\subsection{Industry Characteristics}

Our analysis so far has highlighted the importance of a particular industry characteristic, the source of firm heterogeneity, for the composition of international commerce. We now investigate how the sorting of firms into different modes of foreign market access changes with other industry characteristics, namely transport costs and the fixed cost of cross-border M\&A. As our analysis will show, the effects of these industry characteristics will be very different in industries $M$ and $N$. For simplicity, we assume that the two countries are identical, $Y^{1}=Y^{2}$. For notational convenience, we henceforth drop country indices.

Mobility of Capabilities. We seek to analyze the effects of a change in $\delta$, the degree of mobility of capability $n$.

Proposition 5 Consider an increase in $\delta$, the degree of mobility of capability $n$. (a) Then, in industry $M$,

$$
d S<0, \quad d m_{0}<0, \quad d m_{1}<0, d m_{2}>0 .
$$

(b) Then, in industry $N$,

$$
d S<0, \quad d n_{0}>0, d n_{1}<0, d n_{2}<0 .
$$

For firms engaging in exporting the level of (foreign) market size is proportional to $S \delta T$, for firms engaging in greenfield FDI it is proportional to $S \delta$, while for firms engaging in crossborder M\&A it is proportional to $S$. In both industries, holding fixed the number of entrants

\footnotetext{
${ }^{7}$ The closed-economy models of Asplund and Nocke (2003) and Nocke (2003) predict that firms have to be more efficient to survive in larger markets, which is in line with the predictions for industry $N$. However, their result is due to an endogenous increase in the intensity of price competition in larger markets.

${ }^{8}$ See, for instance, Yeaple (2003) and Carr, Markusen, and Maskus (2002).
} 
and the thresholds, the direct effect of an increase in $\delta$ is to reduce the markup-adjusted residual demand level $S$. However, the induced fractional increase in $S$ is smaller than the (exogenous) fractional increase in $\delta$, and so $S \delta$ increases. Consequently, the payoff from cross-border mergers tends to fall, while the payoff from exporting and greenfield FDI tends to rise. However, since firms engaging in greenfield FDI do not have to incur transport costs, the fractional increase in the payoff from greenfield FDI is greater than that from exporting. The effect of the increase in $\delta$ on the thresholds follows immediately from these observations. However, the relative size of the movements in the thresholds is determined by the merger market clearing conditions.

In both industries, the primary effect of an increase in the mobility of the less mobile capability $n$ is to change the composition of foreign direct investment. As the mobility of $n$ increases, the ratio between firms engaging in cross-border M\&A and those engaging in greenfield FDI decreases. In the limit as $\delta \rightarrow 1$, cross-border mergers disappear, while in the limit as $\delta \rightarrow 0$, greenfield FDI disappears. Hence, for cross-border M\&A to occur, there must be some firm capabilities that are imperfectly mobile internationally.

Transport Costs. We now turn to the effects of a change in transport costs (or tariffs) on the composition of international commerce.

Proposition 6 Consider a decrease in transport costs, i.e., an increase in T. (a) Then, in industry $M$,

$$
d S<0, d m_{0}<0, \quad d m_{1}>0, d m_{2}>0 .
$$

(b) Then, in industry $N$,

$$
d S<0, d n_{0}>0, d n_{1}<0, d n_{2}>0 .
$$

As pointed out above, for firms engaging in exporting the level of (foreign) market size is proportional to $S \delta T$, for firms engaging in greenfield FDI it is proportional to $S \delta$, while for firms engaging in cross-border M\&A it is proportional to $S$. In both industries, holding fixed the number of entrants and the thresholds, the direct effect of an increase in $T$ is to reduce the markup-adjusted residual demand level $S$. However, the induced fractional increase in $S$ is smaller than the (exogenous) fractional increase in $T$, and so $S T$ increases. Consequently, 
the payoff from cross-border mergers and greenfield FDI tends to fall, while the payoff from exporting tends to rise. However, since firms engaging in cross-border mergers face a larger foreign demand than firms engaging in greenfield FDI, the fractional decrease in the payoff from cross-border M\&A is greater than that from greenfield FDI. The effect of the increase in $T$ on the thresholds follows immediately from these observations. However, the relative size of the movements in the thresholds is determined by the merger market clearing conditions.

In both industries, the primary effect of a decrease in transport costs, i.e., an increase in $T$, is to change the fraction of firms engaging in foreign direct investment. As $T$ increases, the fraction of entrants engaging in either cross-border M\&A or greenfield FDI decreases. However, as long as $\delta$ is sufficiently small, cross-border mergers occur even in the limit as $T \rightarrow 1$, while greenfield FDI disappears in the limit. This may explain why most FDI between the US and Europe, where trade barriers are small, is in the form of cross-border M\&A rather than greenfield FDI. In contrast, a much larger fraction of FDI between the North and the South, where trade barriers are large, is in the form of greenfield FDI.

General Discussion of Industry Effects. The effect of changes in $\delta$ and $T$ has very different implications for the distribution of firm efficiencies in the two industries. In industry $M$, an increase in either $\delta$ or $T$ reduces the efficiency $\left(m_{0}\right)$ of the marginal active firm, while in industry $N$, the effect on $n_{0}$ is the opposite. The reason for this dichotomy is that the composition of international commerce is very different in the two industries. In industry $M$, the marginal active firm is an exporter, while in industry $N$, it is a firm engaging in cross-border M\&A. Since an increase in $\delta$ or $T$ makes exporting relatively more attractive and cross-border mergers relative less attractive, $m_{0}$ has to fall in industry $M$, while $n_{0}$ rises in industry $N$. These results have important implications for the growing empirical literature on the effects of trade policies on aggregate productivity. Crucially, our theory shows that the empirical relationship between trade costs and aggregate industry efficiency cannot be predicted without prior knowledge of the source of firm heterogeneity in that industry. 


\section{Conclusion}

In this paper, we have developed a theory of international commerce in which firms can choose between three different modes of foreign market access: exporting, greenfield FDI, and crossborder mergers and acquisitions. Our framework is based on three key ideas. First, there is heterogeneity in firms' capabilities. Second, these capabilities differ in their degree of international mobility. Third, capabilities are traded in a merger market, and so their price is determined by endogenous supply and demand. We have applied this framework to address two questions: (1) what are the characteristics of firms that choose the different modes of foreign market access, and (2) what are the effects of country and industry characteristics on the composition of international commerce and the distribution of firm efficiencies? The answers to these questions are of importance to a growing empirical literature on firm heterogeneity and the composition of international commerce.

A main result of our analysis is that the source of firm heterogeneity is a critical industry characteristic for the composition of international commerce. Depending on whether firms differ in their mobile or non-mobile capabilities, cross-border M\&A involves either the most or the least efficient active firms. The source of firm heterogeneity also plays an important role for the effects of country and industry characteristics on the distribution of firm efficiencies.

Our analysis has also highlighted the importance of the merger market clearing condition for the predictions of our model. Since the changes in country and industry characteristics directly impact upon the supply and demand of capabilities, the effect of these characteristics on aggregate industry efficiency is mediated by the merger market.

While the three key ideas mentioned above are critical for our results, the particular assignment of different types of capabilities to different "activities" is not. In this paper, we have considered two types of activities, production and marketing, each of which requires a different type of capability. More generally, what matters in our framework is that different activities require capabilities that vary in their degree of international mobility, and that these activities are complementary in generating profits.

Our theory may also be used as a framework to inform government policies toward interna- 
tional commerce. Because cross-border M\&A involves the acquisition of a local firm by a foreign multinational enterprise, cross-border M\&A brings "less" to the host country's economy than greenfield FDI. Moreover, as our analysis has shown, firms with different capabilities choose different modes of foreign market access. Hence, the optimal government policy toward foreign direct investment should be tailored to the particular type of FDI: greenfield vs. cross-border M\&A. A rigorous analysis of the policy implications of our theory, however, raises a number of modeling issues (government objectives, set of policy instruments) that we plan to address in a separate paper.

\section{Appendix: Proofs}

Proof of lemma 1. The endogenous variable $u$ in country $k$ may be written as a function of the country sizes, $f\left(Y^{k}, Y^{l}\right)$, where the first argument refers to the own country size, and the second argument to the size of the other country. Assuming differentiability of $f$ (which can be verified to hold for our problem at hand), the endogenous change in the value of $u^{k}$ is given by

$$
d u^{k}=f_{1}\left(Y^{k}, Y^{l}\right) d Y^{k}+f_{2}\left(Y^{k}, Y^{l}\right) d Y^{l}
$$

where $f_{i}$ is the derivative of $f$ with respect to its $i$ th argument. Similarly, the endogenous change in the value of $u^{l}$ is equal to

$$
d u^{l}=f_{1}\left(Y^{l}, Y^{k}\right) d Y^{l}+f_{2}\left(Y^{l}, Y^{k}\right) d Y^{k} .
$$

Since $Y^{k}=Y^{l}$, we have $f_{i}\left(Y^{k}, Y^{l}\right)=f_{i}\left(Y^{l}, Y^{k}\right)$. Moreover, by assumption, $d Y^{k}=-d Y^{l}$, and so $d u^{l}$ can be rewritten as

$$
\begin{aligned}
d u^{l} & =-f_{1}\left(Y^{k}, Y^{l}\right) d Y^{k}-f_{2}\left(Y^{k}, Y^{l}\right) d Y^{l} \\
& =-d u^{k}
\end{aligned}
$$

Proof of proposition 3. Since the two countries are (initially) of the same size, the merger market clearing condition (7) implies that

$$
\mu=2-H\left(m_{0}^{k}\right)-H\left(m_{2}^{k}\right) .
$$


Taking the logarithm of the merger market clearing condition, then forming the total derivative, and applying lemma 1 , yields

$$
\frac{d E^{k}}{E^{k}}=\frac{h\left(m_{2}^{k}\right) d m_{2}^{k}-h\left(m_{0}^{k}\right) d m_{0}^{k}}{2\left[1-H\left(m_{2}^{k}\right)\right]} .
$$

Taking the total derivative of the free entry condition (8), and inserting (21), we obtain

$$
2\left[1-H\left(m_{2}^{k}\right)\right] d V^{k}(1)+\Gamma d S^{k}=0
$$

where

$$
\Gamma \equiv(1-T \delta) \Psi\left(m_{0}^{k}\right)-(1-T) \delta \Psi\left(m_{1}^{k}\right)-(1-\delta) \Psi\left(m_{2}^{k}\right)
$$

Observe that changes in the thresholds $m_{i}^{k}$ cancel out (i.e., $d m_{i}^{k}=0$ ). This is due to the envelope theorem and the fact that the thresholds are efficient from the firms' point of view in that they maximize (expected) profits. Note that $\Gamma>0$ since $\Psi\left(m_{0}^{k}\right)>\Psi\left(m_{1}^{k}\right)>\Psi\left(m_{2}^{k}\right)$. It follows that $V^{k}(1)$ and $d S^{k}$ move in opposite directions, i.e., $d V^{k}(1) d S^{k}<0$ whenever $d S^{k} \neq 0$.

Taking the total derivatives of the threshold equations (4) to (6) and using lemma 1, yields

$$
\begin{aligned}
\frac{d m_{0}^{k}}{m_{0}^{k}} & =\frac{d V^{k}(1)}{V^{k}(1)}-\left(\frac{1-T \delta}{1+T \delta}\right) \frac{d S^{k}}{S^{k}} \\
\frac{d m_{1}^{k}}{m_{1}^{k}} & =\frac{d S^{k}}{S^{k}} \\
\frac{d m_{2}^{k}}{m_{2}^{k}} & =\frac{d S^{k}}{S^{k}}-\frac{d V^{k}(1)}{V^{k}(1)+F_{f}-F_{c}} .
\end{aligned}
$$

We thus obtain that $m_{1}^{k}$ and $m_{2}^{k}$ move in the same direction as demand level $S^{k}$, while $m_{0}^{k}$ moves in the opposite direction. That is, $d m_{1}^{k} d S^{k}>0, d m_{2}^{k} d S^{k}>0$, and $d m_{0}^{k} d S^{k}<0$, provided $d S^{k} \neq 0$. From equation (22), it then follows that the mass of entrants $E^{k}$ and demand level $S^{k}$ move in the same direction, i.e., $d E^{k} d S^{k}>0$.

Finally, taking the total derivative of equation (10), we obtain

$$
\frac{d S^{k}}{S^{k}}+\frac{\frac{d E^{k}}{E^{k}} \Gamma+\left\{(1-T \delta) \Psi^{\prime}\left(m_{0}^{k}\right) d m_{0}^{k}-(1-T) \delta \Psi^{\prime}\left(m_{1}^{k}\right) d m_{1}^{k}-(1-\delta) \Psi^{\prime}\left(m_{2}^{k}\right) d m_{2}^{k}\right\}}{(1+T \delta) \Psi\left(m_{0}^{k}\right)+(1-T) \delta \Psi\left(m_{1}^{k}\right)+(1-\delta) \Psi\left(m_{2}^{k}\right)}=\frac{d Y^{k}}{Y^{k}} .
$$

Since $\Psi^{\prime}\left(m_{i}\right)<0$, the term in curly brackets has the same sign as $d E^{k}$ and $d S^{k}$. Hence, we must have $d S^{k}>0$ because $d Y^{k}>0$ by assumption. The assertion on $W^{k}(m)$ follows immediately from equation (3), $d S^{k}=-d S^{l}>0$, and $d V^{k}(1)=-d V^{l}(1)<0$. 
Proof of proposition 4. Taking the total derivative of the equation for $n_{0}^{k}$, (12) or, equivalently, (18), and applying lemma 1, we obtain $d W(1)=0$. Next, taking the total derivative of the equation for $n_{2}^{k}$, (14), gives

$$
\frac{d S^{k}}{S^{k}}=\frac{d n_{2}^{k}}{n_{2}^{k}}
$$

Hence, the threshold $n_{2}^{k}$ moves in the same direction as demand level $S^{k}$, i.e., $d n_{2}^{k} d S^{k}>0$, provided $d S^{k} \neq 0$. Similarly, from the equation for $n_{1}^{k}$, (13), it follows that

$$
d n_{0}^{k}+T \delta d n_{1}^{k}=-\left[n_{0}^{k}-T \delta n_{1}^{k}\right] \frac{d S^{k}}{S^{k}}
$$

where the term in brackets on the r.h.s. is positive since, with initially identical countries,

$$
n_{0}^{k}-T \delta n_{1}^{k}=\frac{F_{f}}{S^{k}} .
$$

Consider now the free entry condition, equation (17). Taking the total derivative, and using (25) and (26), yields

$$
\frac{d S^{k}}{S^{k}}\left\{B-\left[G\left(n_{1}^{k}\right)-G\left(n_{0}^{k}\right)\right] n_{0}^{k}\right\}=\left[G\left(n_{1}^{k}\right)-G\left(n_{0}^{k}\right)\right] d n_{0}^{k}
$$

where

$$
B \equiv \int_{n_{0}^{k}}^{n_{1}^{k}} n d G(n)+(1-T \delta) \int_{n_{1}^{k}}^{n_{2}^{k}} n d G(n)+(1-\delta) \int_{n_{2}^{k}}^{\infty} n d G(n) .
$$

Note that the term in curly brackets on the left-hand side of (28) is positive. It is then immediate that the threshold $n_{0}^{k}$ moves in the same direction as demand level $S^{k}$, i.e., $d n_{0}^{k} d S^{k}>0$, assuming $d S^{k} \neq 0$. From (26), it follows that $n_{1}^{k}$ has to move in the opposite direction, i.e., $d n_{1}^{k} d S^{k}<0$. Taking the total derivative of the merger market clearing condition (15), we obtain

$$
\frac{d E^{k}}{E^{k}}=\frac{g\left(n_{0}^{k}\right) d n_{0}^{k}-g\left(n_{1}^{k}\right) d n_{1}^{k}}{G\left(n_{1}^{k}\right)-G\left(n_{0}^{k}\right)} .
$$

Since $n_{0}^{k}$ moves in the same direction as $S^{k}$, while $n_{1}^{k}$ moves in the opposition direction, it follows that the mass of entrants, $E^{k}$, moves in the same direction as $S^{k}$, i.e., $d E^{k} d S^{k}>0$.

It remains to show that demand level $S^{k}$ moves in the same direction as income (or country size) $Y^{k}$. Totally differentiating $(20)$, yields

$$
\begin{aligned}
\frac{\beta}{\sigma} d Y^{k}= & \frac{\beta Y^{k}}{\sigma} \frac{d S^{k}}{S^{k}}+S^{k} B d E^{k}-S^{k} E^{k} n_{0}^{k} g\left(n_{0}^{k}\right) d n_{0}^{k} \\
& +S^{k} E^{k} T \delta n_{1}^{k} g\left(n_{1}^{k}\right) d n_{1}^{k}+S^{k} E^{k}(1-T) \delta n_{2}^{k} g\left(n_{2}^{k}\right) d n_{2}^{k},
\end{aligned}
$$


Substituting (29) into (30), and using (25), (26), and (28), yields

$$
\begin{aligned}
\frac{\beta}{\sigma} d Y^{k}= & \frac{d S^{k}}{S^{k}}\left\{\frac{\beta Y^{k}}{\sigma}+S^{k} E^{k} \frac{g\left(n_{1}^{k}\right)}{T \delta} n_{0}^{k}\left(n_{0}^{k}-T \delta n_{1}^{k}\right)+S^{k} E^{k}(1-T) \delta\left(n_{2}^{k}\right)^{2} g\left(n_{2}^{k}\right)\right. \\
& \left.-S^{k} E^{k} n_{1}^{k} g\left(n_{1}^{k}\right)\left(n_{0}^{k}-T \delta n_{1}^{k}\right)\right\}+d n_{0}^{k} S^{k} E^{k}\left\{\frac{g\left(n_{0}^{k}\right)+g\left(n_{1}^{k}\right) / T \delta}{G\left(n_{1}^{k}\right)-G\left(n_{0}^{k}\right)} B\right. \\
& \left.+\frac{g\left(n_{1}^{k}\right)}{T \delta}\left(n_{0}^{k}-T \delta n_{1}^{k}\right)-n_{0}^{k} g\left(n_{0}^{k}\right)-n_{1}^{k} g\left(n_{1}^{k}\right)\right\} .
\end{aligned}
$$

Collecting terms and using (27), this equation can be rewritten as

$$
\begin{aligned}
\frac{\beta}{\sigma} d Y^{k}= & \frac{d S^{k}}{S^{k}}\left\{\frac{\beta Y^{k}}{\sigma}+S^{k} E^{k}\left[(1-T) \delta\left(n_{2}^{k}\right)^{2} g\left(n_{2}^{k}\right)+\frac{\left(n_{0}^{k}-T \delta n_{1}^{k}\right)^{2}}{T \delta} g\left(n_{1}^{k}\right)\right]\right\} \\
& +d n_{0}^{k} S^{k} E^{k}\left\{\frac{2 g\left(n_{1}^{k}\right) F_{f}}{S^{k} T \delta}+\frac{g\left(n_{0}^{k}\right)+g\left(n_{1}^{k}\right) / T \delta}{G\left(n_{1}^{k}\right)-G\left(n_{0}^{k}\right)}\left[\int_{n_{0}^{k}}^{n_{1}^{k}}\left(n-n_{0}^{k}\right) d G(n)\right.\right. \\
& \left.\left.+(1-T \delta) \int_{n_{1}^{k}}^{n_{2}^{k}} n d G(n)+(1-\delta) \int_{n_{2}^{k}}^{\infty} n d G(n)\right]\right\} .
\end{aligned}
$$

Since the curly brackets on the r.h.s. are positive, and $d n_{0}^{k} d S^{k}>0$, it follows that demand level $S^{k}$ and income $Y^{k}$ move in the same direction, i.e., $d S^{k}>0$ since $d Y^{k}>0$ by assumption.

Lemma 2 Suppose the two countries are of the same size, i.e., $Y^{1}=Y^{2}$. Then, in industry $M$, any change in exogenous variables (except $\mu$ ) causes the thresholds $m_{0}^{k}$ and $m_{2}^{k}$ to move in opposite directions. That is, $d m_{0}^{k} d m_{2}^{k}<0$, provided $d m_{0}^{k} \neq 0$ or $d m_{2}^{k} \neq 0$.

Proof. Since the two countries are identical, the merger market clearing condition (7) implies that

$$
\mu=2-H\left(m_{0}^{k}\right)-H\left(m_{2}^{k}\right)
$$

Taking the total derivative (and assuming $d \mu=0$ ), we obtain

$$
h\left(m_{0}^{k}\right) d m_{0}^{k}=-h\left(m_{2}^{k}\right) d m_{2}^{k}
$$

which establishes the result.

Lemma 3 Suppose the two countries are of the same size, i.e., $Y^{1}=Y^{2}$. Then, in industry $N$, any change in exogenous variables (except $\nu$ ) causes the thresholds $n_{0}^{k}$ and $n_{1}^{k}$ to move in opposite directions. That is, $d n_{0}^{k} d n_{1}^{k}<0$, provided $d n_{0}^{k} \neq 0$ or $d n_{1}^{k} \neq 0$. 
Proof. Since the two countries are identical, the market clearing condition for mobile capabilities, equation (16), implies that

$$
2(1-\nu)=G\left(n_{0}^{k}\right)+G\left(n_{1}^{k}\right)
$$

The assertion follows immediately.

Proof of proposition 5. (a) We begin by totally differentiating the threshold condition for $m_{1}$, equation (5),

$$
\frac{d m_{1}}{m_{1}}=-\frac{d S}{S}-\frac{d \delta}{\delta}
$$

Total differentiation of the free entry condition (8), and using (7), yields

$$
\frac{d S}{S}=-\frac{T\left\{\Psi\left(m_{0}\right)-\Psi\left(m_{1}\right)\right\}+\left\{\Psi\left(m_{1}\right)-\Psi\left(m_{2}\right)\right\}}{(1+T \delta) \Psi\left(m_{0}\right)+(1-T) \delta \Psi\left(m_{1}\right)+(1-\delta) \Psi\left(m_{2}\right)} d \delta .
$$

From the last equation, we obtain that $d S d \delta<0$. Since the absolute value of the coefficient in front of $d \delta$ is less than one, it then follows from equation (31) that $d m_{1} d \delta<0$. Combining the remaining two threshold conditions, (4) and (6), and totally differentiating, yields

$$
S(1-\delta) m_{2}=S(1+T \delta) m_{0}+F_{f}-F_{c}
$$

Totally differentiating this expression and rearranging yields

$$
(1-\delta) d m_{2}=(1+T \delta) d m_{0}-\left(m_{2}-m_{0}\right) \frac{d S}{S}+\left(m_{2}+T m_{0}\right) \delta\left\{\frac{d \delta}{\delta}+\frac{d S}{S}\right\} .
$$

By substituting expression (32) into the last term in brackets, it can be established that this bracketed term must be positive. Since $d S d \delta<0$, it follows that the second term is of the same sign as $d \delta$. Since $m_{2}$ and $m_{0}$ must move in opposite directions for the merger market to clear (see equation (7)), it follows that $d m_{2} d \delta>0$ and $d m_{0} d \delta<0$.

(b) Imposing symmetry, and totally differentiating the three threshold conditions, (12), (13), and (14), yields

$$
\begin{gathered}
d W(1)=2\left[S d n_{0}+n_{0} d S\right] \\
d n_{0}-T \delta d n_{1}=T n_{1} d \delta-\frac{d S}{S}\left[n_{0}-T \delta n_{1}\right]
\end{gathered}
$$

and

$$
\frac{d n_{2}}{n_{2}}=-\left\{\frac{d S}{S}+\frac{d \delta}{\delta}\right\}
$$


From the merger market clearing condition for mobile capabilities, equation (16), we obtain

$$
\nu=\frac{1}{2}\left[2-G\left(n_{0}\right)-G\left(n_{1}\right)\right] .
$$

Totally differentiating the free entry condition (17), yields

$$
\begin{aligned}
& \nu d W(1)+d S\left\{\Phi\left(n_{0}^{k}\right)+T \delta \Phi\left(n_{1}^{k}\right)+(1-T) \delta \Phi\left(n_{2}^{k}\right)\right\} \\
& -S\left\{\left[1-G\left(n_{0}\right)\right] d n_{0}+T \delta\left[1-G\left(n_{1}\right)\right] d n_{1}+(1-T) \delta\left[1-G\left(n_{2}\right)\right] d n_{2}\right\} \\
= & -S\left\{T \Phi\left(n_{1}\right)+(1-T) \Phi\left(n_{2}\right)\right\} d \delta .
\end{aligned}
$$

Inserting equations (33) to (36) into this equations and simplifying, we obtain

$$
\frac{d S^{k}}{S^{k}}=-\frac{T \Theta\left(n_{1}^{k}\right)+(1-T) \Theta\left(n_{2}^{k}\right)}{\Theta\left(n_{0}^{k}\right)+T \delta \Theta\left(n_{1}^{k}\right)+(1-T) \delta \Theta\left(n_{2}^{k}\right)} d \delta .
$$

Hence, $d S^{k} d \delta<0$. Since the absolute value of the constant in front of $d \delta$ is less than one, it follows from equation (35) that $d n_{2} d \delta<0$. Moreover, since $n_{0}$ and $n_{1}$ have to move in opposite directions for the merger market to clear (lemma 3), and since $n_{0}>T \delta n_{1}$ (as can be seen from (13)), we establish that $d n_{0} d \delta>0$ and $d n_{1} d \delta<0$.

Proof of proposition 6. (a) Imposing symmetry and taking the total derivative of the free entry condition (8), yields

$$
\frac{d S}{S}=-\frac{\delta\left(\Psi\left(m_{0}\right)-\Psi\left(m_{1}\right)\right)}{(1+T \delta) \Psi\left(m_{0}\right)+(1-T) \delta \Psi\left(m_{1}\right)+(1-\delta) \Psi\left(m_{2}\right)} d T .
$$

As in the proof of proposition 3, changes in the thresholds $m_{i}$ cancel out (due to the envelope theorem). Here, however, changes in the market price of working plants, $V(1)$, cancel out as well (if one takes the merger market clearing condition (7) into account) because the two countries are identical. Since the term in front of $d T$ in equation (37) is negative, $S$ and $T$ move in opposite directions, and hence $d S<0$.

Taking the total derivative of the equation for $m_{1}$ (see (5)), we obtain

$$
\frac{d m_{1}}{m_{1}}=\frac{d T}{1-T}-\frac{d S}{S}
$$

Both terms on the r.h.s. of the equation are positive, and so $d m_{1}>0$. Totally differentiating the threshold conditions for $m_{0}$ and $m_{2}$, equations (4) and (6), yields

$$
(1+T \delta) S d m_{0}+(1+T \delta) m_{0} d S+\delta S m_{0} d T=d V(1)
$$


and

$$
(1-\delta) S d m_{2}+(1-\delta) m_{2} d S=d V(1)
$$

Substituting out $d V(1)$, and rearranging, we obtain

$$
(1-\delta) d m_{2}=(1+T \delta) d m_{0}-(1-\delta) m_{2} \frac{d S}{S}+m_{0} \delta\left\{d T+\left(\frac{1+T \delta}{\delta}\right) \frac{d S}{S}\right\} .
$$

Since $d S<0$, the second term on the r.h.s. of (38) is positive. Further, from (37), it follows that the term in curly brackets is positive as well. Hence, if $d m_{0}>0$, we would have $d m_{2}>0$. However, this contradicts lemma 2 , which states that $m_{0}$ and $m_{2}$ move in opposite directions. Consequently, we must have $d m_{0}<0$ and $d m_{2}>0$.

(b) Imposing symmetry, and totally differentiating the condition for threshold $n_{0}$, equation (12), we obtain

$$
d W(1)=2\left[n_{0} d S+S d n_{0}\right]
$$

Similarly, from the equation for $n_{1}^{k},(13)$, we derive

$$
d T=\left(\frac{n_{0}-T \delta n_{1}}{n_{1} \delta}\right) \frac{d S}{S}+\frac{d n_{0}-T \delta d n_{1}}{n_{1} \delta} .
$$

Taking the total derivative of equation (14), the condition for threshold $n_{2}$, yields

$$
\frac{d n_{2}}{n_{2}}=\frac{d T}{1-T}-\frac{d S}{S}
$$

Totally differentiating the free entry condition, (17), we get

$$
\begin{aligned}
& \nu d W(1)+d S\left\{\Phi\left(n_{0}\right)+T \delta \Phi\left(n_{1}\right)+(1-T) \delta \Phi\left(n_{2}\right)\right\} \\
& -S\left\{\left[1-G\left(n_{0}\right)\right] d n_{0}+T \delta\left[1-G\left(n_{1}\right)\right] d n_{1}+(1-T) \delta\left[1-G\left(n_{2}\right)\right] d n_{2}\right\} \\
= & -S^{k} \delta\left\{\Phi\left(n_{1}\right)-\Phi\left(n_{2}\right)\right\} d T .
\end{aligned}
$$

From the merger market clearing condition (16), we can replace $\nu$ in (42) by $\nu=\left[2-G\left(n_{0}\right)\right.$ $\left.-G\left(n_{1}\right)\right] / 2$. Moreover, using equations (39) to (41), we can rewrite (42) as

$$
\frac{d S}{S}\left\{\Theta\left(n_{0}\right)+T \delta \Theta\left(n_{1}\right)+(1-T) \delta \Theta\left(n_{2}\right)\right\}=-\delta\left\{\Theta\left(n_{1}\right)-\Theta\left(n_{2}\right)\right\} d T .
$$

Clearly, the terms in curly brackets are positive. Hence, we have $d S<0$, because $d T>0$ by assumption. From (40) and lemma 3, and noting that $n_{0}>T \delta n_{1}$ (which follows from (13)), we obtain that $d n_{0}>0$ and $d n_{1}<0$. Since $d T>0$ and $d S<0$, from equation (41) we obtain that $d n_{2}>0$. 
Nocke \& Yeaple: Mergers and the Composition of International Commerce 38

\section{References}

Antras, P., And E. Helpman (2003): "Global Sourcing," Journal of Political Economy, Forthcoming.

Asplund, M., And V. Nocke (2003): "Firm Turnover in Imperfectly Competitive Markets," PIER Working Paper 03-010, University of Pennsylvania.

Bernard, A. B., J. Eaton, J. B. Jensen, and S. Kortum (2003): "Plants and Productivity in International Trade," American Economic Review, 93(4), 1268-1290.

Caves, R. E. (1996): Multinational Enterprise and Economic Analysis. Cambridge University Press, 2nd edn.

HeAd, K., And J. RiEs (1997): "International Mergers and Welfare under Decentralized Competition Policy," Canadian Journal of Economics, 30, 1104-1123.

Helpman, E., M. Melitz, and S. Yeaple (2004): "Exports versus FDI with Heterogeneous Firms," American Economic Review, Forthcoming.

Horn, H., AND L. Persson (2001): "The Equilibrium Ownership of an International Oligopoly," Journal of International Economics, 53, 307-333.

Jovanovic, B., And P. Rousseau (2002): "The Q-Theory of Mergers," American Economic Review, 92, 198-204.

Kamien, M. I., And I. ZAng (1990): "The Limits of Monopolization through Acquisition," Quarterly Journal of Economics, 105(2), 465-499.

Lucas, R. E. (1978): "On the Size Distribution of Business Firms," Bell Journal of Economics, $9(2), 508-523$.

Markusen, J. (1984): "Multinationals, Multi-Plant Economies, and the Gains from Trade," Journal of International Economics, 16, 205-226. 
Nocke \& Yeaple: Mergers and the Composition of International Commerce 39

Maurin, E., D. Thesmar, and M. Thoenig (2002): "Globalization and the Demand for Skill: An Export Channel," CEPR Working Paper 3406, Centre for Economic Policy Research.

Melitz, M. (2003): "The Impact of Trade on Intra-Industry Reallocations and Aggregate Industry Productivity," Econometrica, 71(6), 1695-1725.

NeARY, J. P. (2003): "Cross-Border Mergers as Instruments of Comparative Advantage," Mimeo.

Nocke, V. (2000): "Monopolisation and Industry Structure," Economics Working Paper 2000W27, Nuffield College, Oxford.

(2003): “A Gap for Me: Entrepreneurs and Entry," PIER Working Paper 03-019, University of Pennsylvania.

Rosen, S. (1981): "The Economics of Superstars," American Economic Review, 81(5), 845858.

Yeaple, S. (2003): "The Role of Skill Endowments in the Structure of U.S. Outward Foreign Direct Investment," Review of Economics and Statistics, 85(3), 726-734. 